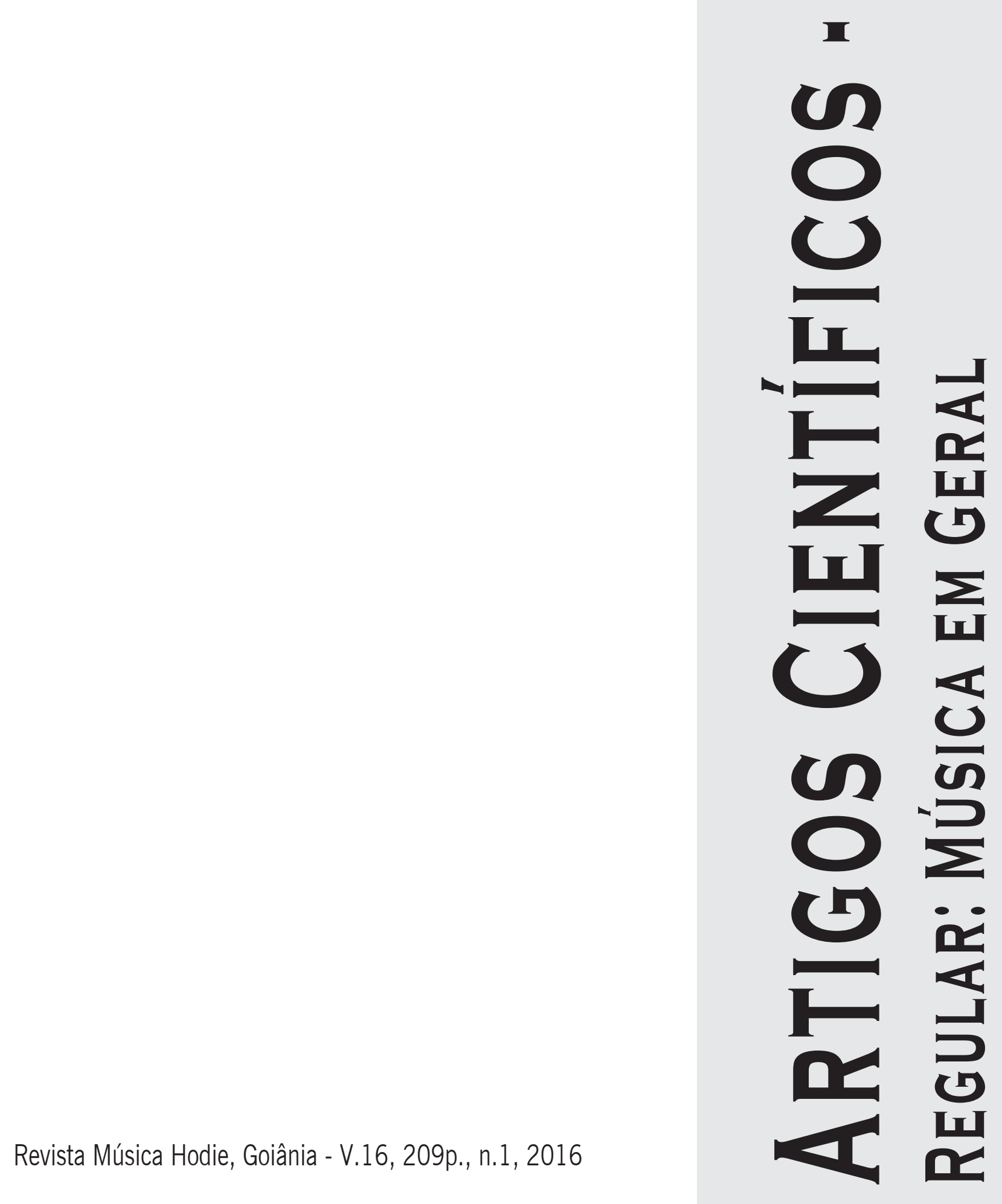




\title{
A formulação da Favola in musica de Jacopo Peri: uma tradução e estudo do prefácio a Euridice (1600)
}

\author{
Gustavo Angelo Dias (Universidade Federal de Pelotas, Pelotas, RS, Brasil) \\ gustavoangelod@gmail.com \\ Helena Jank (Universidade Estadual de Campinas, Campinas, SP, Brasil) \\ hjank@iar.unicamp.br
}

\begin{abstract}
Resumo: Neste artigo buscamos tecer uma visão da proposta monódica de Jacopo Peri (1561-1633), compositor italiano pertencente à geração que estabeleceu as bases da monodia acompanhada e do stile rappresentativo, pressupostos essenciais ao desenvolvimento do estilo barroco e do surgimento da ópera. Para tanto, apresentamos uma tradução do primeiro texto a apresentar as características e os propósitos estéticos da monodia acompanhada, o prefácio à ópera Euridice (Florença, 1600), contextualizada por uma abordagem dos aspectos históricos envolvidos no desenvolvimento e na formulação da monodia e da publicação da obra. Buscamos também tecer uma análise dos elementos de performance envolvidos no texto, nos atendo às peculiaridades da pesquisa de Peri e aos ideais buscados pelo autor de retomada de um estilo de canto que, segundo acreditava, teria sido utilizado nas encenações das tragédias na antiguidade.
\end{abstract}

Palavras-chave: Monodia acompanhada; Música barroca italiana; Ópera; Jacopo Peri (1561-1633).

The formulation of Jacopo Peri's favola in musica: a traslation and study of Euridice's preface (1600)

Abstract: In this article we seek to build a vision of the monodic proposition by Jacopo Peri (1561-1633), Italian composer of the generation that laid the foundations of accompanied monody and the stile rappresentativo, key assumptions for the development of the Baroque style and the emergence of Opera. Therefore, we present a translation of the first text to present the characteristics and aesthetic purposes of accompanied monody, the preface to the Opera 'Euridice' (Florence, 1600), contextualized by an approach of historical aspects involved in the development and formulation of monody and the publication the work. We also seek to analyse the performance elements found in the text, and the peculiarities of Peri' research and the ideals pursued by the author of resumption of that singing style, he believed, it would have been used in performances of tragedies in antiquity.

Keywords: Accompaigned monody; Italian Baroque music; Opera; Jacopo Peri (1561-1633).

La formulación de la favola in música de Jacopo Peri: una traducción y estudio dela prefacio a la Euridice (1600)

Resumen: En este artículo tratamos de tejer una visión de la propuesta monódica de Jacopo Peri (1561 hasta 1633), compositor italiano que pertenece a la generación que estableció las bases de la monodia acompañada y del stile rappresentativo, presupuestos esenciales para el desarrollo del estilo barroco y del surgimiento de la ópera. Por lo tanto, presentamos una traducción del primer texto que presentó las características y propósitos estéticos de la monodia acompañada, el prefacio de la ópera Euridice (Florencia, 1600), contextualizada por un abordaje de los aspectos históricos envueltos en el desarrollo y formulación de la monodia y de la publicación de la obra. También tratamos de tejer un análisis de los elementos de performance envueltos en el texto, ateniéndose a las peculiaridades de la investigación de Peri y a los ideales perseguidos por el autor de la reanudación de ese estilo de canto que, a su juicio, habría sido utilizado en representaciones de tragedias en la antigüedad.

Palabras clave: Monodia acompañada, Música barroca italiana; Ópera; Jacopo Peri (1561-1633).

Neste trabalho apresentamos uma tradução comentada do prefácio à ópera Euridice (Florença, 1600) de Jacopo Peri (1561-1633), buscando contextualizar o surgimento deste gênero musical em fins do século XVI e suas relações com a monodia, com o teatro italiano seiscentista, com o stile rappresentativo ${ }^{1}$ e com a busca pela retomada de ideais musicais da antiguidade clássica. A par dos pressupostos técnicos e estéticos encontrados neste prefácio, concebido como uma introdução e justificativa da composição em estilo monódico encontramos no texto de Peri a fundamentação do autor para a criação de um gênero que fundia teatro e música, ou seja, a ópera. O surgimento deste gênero tem origem tanto na prática musical em reuniões dos círculos de nobres florentinos quanto na proposta de retomada daquilo que Peri e alguns de seus contemporâneos acreditavam caracterizar a maneira como as tragédias gregas e romanas teriam sido encenadas na antiguidade. 
Quanto a este último aspecto, o prefácio de Peri é uma fonte especialmente interessante, pois dentre os autores que propuseram uma explicação das características da monodia, Peri se destaca pela forma detalhada e aprofundada como aborda a questão do canto nas antigas tragédias, procurando deduzir suas características a partir do que ele e os intelectuais de seu círculo conheciam sobre o assunto e formulando suas próprias soluções para a retomada do estilo de canto da antiguidade no contexto da prática musical de sua época.

O surgimento da ópera (ou favola in musica, como aparece nas primeiras edições ${ }^{2}$ ) se relaciona intrinsecamente ao desenvolvimento da monodia acompanhada, a prática composicional que lançaria as bases para o estilo barroco na música. Partindo da leitura de fontes da antiguidade, os compositores ligados ao surgimento da monodia buscavam uma maneira de compor que desse primazia à expressão dos afetos pelo canto, o que segundo acreditavam seria possível apenas quando o texto fosse cantado a uma só ou a poucas vozes, com um acompanhamento instrumental que a ela se associaria fornecendo suporte harmônico e ressaltando as características dramáticas das palavras. Esta concepção significava o rompimento com a tradição polifônica renascentista, que, segundo a crítica dos partidários da monodia, em seu anseio por alcançar a perfeição e o equilíbrio teria deixado em segundo plano a expressividade do canto em favor da cristalização de um modelo formalista, no qual a palavra seria um mero acessório para uma construção musical apoiada sobre procedimentos contrapontísticos demasiadamente codificados e consolidados ${ }^{3}$.

O texto de Peri permite esclarecer aspectos relacionados à performance não apenas das obras de Peri, mas também de outros compositores contemporâneos ou mesmo posteriores. Compreendemos que, se as peculiaridades de cada autor dizem respeito à sua própria concepção ou estilo pessoal, elas podem por outro lado contribuir para a formação de uma compreensão mais ampla da música de um período, já que são diferentes os aspectos enfatizados por um e outro texto a respeito de uma mesma prática. Desta forma, a tradução aqui apresentada do prefácio de Peri vem se somar a outros textos contemporâneos sobre a monodia já traduzidos para o português, como o prefácio ao Nuove Musiche (1601), de Giulio Caccini (1551-1618), publicado em duas diferentes versões nas teses de Heloisa Muller (USP, 2006) e Conrado Augusto Federici (UNICAMP, 2009).

\section{A monodia acompanhada e a corte dos Medici}

Jacopo Peri pertence à geração que debateu, experimentou e pela primeira vez formulou os princípios composicionais e os pressupostos da monodia acompanhada. Embora esta tenha se desenvolvido de diferentes maneiras ao longo de pelo menos as últimas décadas do século XVI, o ímpeto pela postulação teórica deste estilo ocorre entre 1600 e 1602 , quando se dá "o início da codificação do baixo contínuo, coincidindo precisamente com o desenvolvimento do stile rappresentativo e o rompimento com a polifonia contrapontística no acompanhamento" (NUTI, 2007, p. 19). Neste curto intervalo foram publicadas três obras relevantes em estilo monódico contendo prefácios em que os autores buscaram enunciar e justificar os princípios da nova prática: a ópera Le Musiche Sopra L’Euridice (Florença, 1600), de Jacopo Peri, o cancioneiro Le Nuove Musiche (Florença, 1601), de Giulio Caccini e os Cento Concerti Ecclesiastici (Veneza, 1602), de Lodovico Grossi da Viadana (1564-1627). A novidade trazida nestas obras, como aponta Richard Taruskin em Music in the Seventeenth and Eighteenth Century ${ }^{5}$ (2010), se deve ao momento crucial representado pela publicação. Segundo Taruskin, "o que realmente aconteceu em 1600 não foi uma súbita revolução musical, mas apenas o surgimento em forma impressa de práticas musicais que estiveram 
em processo de formação durante todo o século precedente”ø (p. 809). A publicação destas três obras entre 1600 e 1602, ressalta Taruskin, foi o que permitiu que a monodia rompesse a barreira dos círculos em que era cultivada e fosse apresentada ao mundo, ganhando a apreciação dos músicos e do público e trazendo o estilo monódico "à oficialidade do meio impresso" ${ }^{\prime 7}$ (p. 812).

O berço principal da monodia é Florença, onde dois conjuntos de intelectuais, artistas e humanistas se reuniam em torno do conde Giovanni Bardi e do nobre mecenas e compositor Jacopo Corsi. O grupo ligado a Giovanni Bardi, que ficaria conhecido posteriormente como Camerata Fiorentina ou Camerata Bardi, foi frequentado por figuras influentes na vida artística e literária florentina, como os músicos Giulio Caccini, Vicenzo Galilei (1533-1591), Pietro Strozzi (1550-1609) e Emiliano de' Cavalieri (1550-1602), o dramaturgo Giovanni Battista Guarini (1538-1612), o libretista Ottavio Rinuccini (1562-1621) e o historiador e helenista Girolamo Mei (1519-1594), cujos estudos sobre a música grega forneceriam argumentos para o estabelecimento do canto em estilo monódico.

Ainda que cultivasse certa independência de pesquisa em sua criação, a vanguarda artística e literária desta época necessitava da aceitação de seu trabalho por nobres que agiam como mecenas, contratando diretamente músicos, pintores e escritores ou encomendando obras e apresentações para ocasiões específicas. Neste sentido, os libretistas e compositores ligados ao surgimento da monodia e da ópera tiveram a favor da aplicação de seus ideais a possibilidade de associar-se a uma corte afeita ao humanismo e ao espetáculo: a dinastia dos Medici. Embora a monodia tenha encontrado aceitação em círculos como a Camerata de Giovanni Bardi, como relata Caccini em 1601 em seu Nuove Musiche ${ }^{8}$, foi através dos Medici que ela ganhou espaço para atingir maiores proporções, dando um passo além na busca por uma música que espelhasse os ideais trazidos da antiguidade segundo acreditavam Girolamo Mei, Jacopo Peri e Giulio Caccini. Estes ideais apenas puderam se materializar junto a uma corte intrinsecamente ligada à estética neoclássica da arte humanista e à literatura e o teatro de estilo neoplatônico (influenciado pelo teatro profano da antiguidade grega e romana), funcionando como um espaço privilegiado para o desenvolvimento da monodia e do stile rappresentativo. Junto à corte dos Medici se desenvolveu a Accademia Platonica capitaneada por Marsilio Ficino, principal representante deste movimento na Itália e autor da Theologia Platonica (1482). Para a academia de Ficino, Cosimo de Medici ofereceu a Villa de Careggi, nos arredores de Florença, onde "um seleto grupo de eruditos deu partida, em 1459, ao projeto de conhecer e fazer conhecida a filosofia de Platão e dos neoplatônicos na Itália do Renascimento” (ALBERTI DA ROSA, 2010, p. 36-37), o que teria influência vital na produção literária, dramática e musical a partir da segunda metade do século XVI. Neste contexto, nascem "os discursos abstratos sobre temas de inspiração transcendente como o amor, a beleza, a honra, a graça, e outros, consideravelmente contemplados pelas teorias ficinianas que tiveram ampla ressonância por toda a Itália” (MULLER, p. 131).

Se entre os artistas da renascença a busca por ideais artísticos se baseia muito mais nas premissas filosóficas por eles cultivadas do que na sujeição de sua criação ao motivo religioso que predomina até o quatrocento, há por outro lado a necessidade da ligação profissional a uma corte que compartilhe dos mesmos ideais, ainda que como forma de promover a si mesma como detentora de um refinado senso artístico que serviria de emblema de seu poder e nobreza espiritual.

Em História Social da Arte e da Literatura (2003), Arnold Hauser assinala que é neste ambiente cortesão que floresce "o estilo artístico de uma classe aristocrática, essencialmente culta e internacional” (2003, p. 374), ou seja, o maneirismo. "A fonte de sua influência universal" afirma o autor, "é o absolutismo que se propaga a toda a Europa ocidental e a vo- 
ga das cortes intelectualmente interessadas e artisticamente ambiciosas” (2003, p. 376). Na interpretação de Hauser, isto representou uma "dependência das classes dominantes", que mantinha os humanistas "trabalhando sob a falsa impressão de que eram intelectualmente livres” (2003, p. 351), uma vez que as próprias premissas estéticas sob as quais trabalhavam teriam de ser necessariamente algum ponto de concordância entre os ideais dos intelectuais e artistas e as demandas de uma nobreza que via nas artes um elemento de entretenimento, hedonismo estético e propaganda política.

Hauser analisa que a geração de artistas e humanistas ligados ao cotidiano e às demandas da corte significa a um só tempo uma afirmação social e uma resposta à necessidade de uma nova posição profissional. A ruptura com o ambiente de trabalho mais ou menos massificado que caracteriza o período anterior ao século XVI teria destacado o artista de um meio que lhe garantia uma modesta fonte de sustento e uma relativa estabilidade profissional, porém ao custo de uma certa sujeição ao estilo e à temática praticados nas oficinais que funcionavam como associações de artistas que trabalhavam de forma cooperativa (as guildas).

Segundo Hauser, embora no século XVI os artistas já estivessem profissionalmente desvinculados do modelo de trabalho das guildas, foi a aproximação dos artistas em relação aos humanistas que permitiu a afirmação de seu espaço numa sociedade que tinha em alta consideração os literati, mas tradicionalmente havia associado por muito tempo o artista a uma espécie de artesão de um grau superior. Esta aproximação teria o sentido de

(...) justificar a posição econômica que já tinham conseguido para si mesmos aos olhos da classe alta, dominada pela mentalidade humanista, e para atrair conselheiros científicos, de cuja ajuda necessitavam em suas adaptações de temas mitológicos e históricos a fim de torná-los vendáveis ao mercado. (HAUSER, 2003, p. 331-332)

No contexto florentino de fins do século XVI, a ligação entre os artistas e humanistas em prol de um mesmo ideal prático, já atestado pelas atividades da Camerata Fiorentina desde a década de 1570 e pela intensa troca de influências entre filósofos, helenistas, poetas, músicos e dramaturgos, viria imediatamente de encontro aos interesses dos Medici. No âmbito desta corte fundir-se-iam a produção dos mais destacados nomes das letras e das artes disponíveis no riquíssimo círculo florentino, resultando numa densa confluência de estilos e práticas que teria sido impossível sem o pródigo patrocínio ali encontrado.

Ao longo da segunda metade do século XVI, os espetáculos que a corte dos Medici promovia para deleitar seus membros e convidados tornavam-se cada vez mais elaborados e suntuosos. Músicos, atores, cenógrafos, poetas e dramaturgos eram chamados para a criação de peças de teatro e de música, o que resultou num ambiente que contribuiu para que ambos se associassem. Isto se deu tanto através do uso de entreatos musicais durante as exibições teatrais (os intermédios, ou intermezzi) quanto pela posterior criação uma versão inteiramente musicada da fábula pastoral (favola pastorale).

A fábula pastoral foi gênero teatral que "desenvolveu-se, na metade do século XVI, em função do culto da poesia bucólica clássica, de Teócrito, Ovídio e Virgílio” (COELHO, 2000, p. 33), contando sempre espaço privilegiado na corte dos Medici. Pode-se dizer que a fábula pastoral está ligada a esta família desde seu início, já que a primeira obra do gênero, Orfeo, é de autoria de Angelo Poliziano (1454-1494), escritor e humanista com notável conhecimento da cultura clássica que à época trabalhava para Lorenzo de Medici.

Os intermédios eram pequenas intervenções musicais inicialmente destinadas a meramente assinalar a divisão entre as partes da peça teatral (TARUSKIN, 2010, p. 803). Originários do norte da Itália, estes conjuntos de danças e madrigais faziam parte dos en- 
tretenimentos da corte florentina já na primeira metade do século XVI, guardando sempre relações com a mitologia clássica e a estética neoplatônica. Em 1565 um conjunto de intermédios foi apresentado juntamente à comédia La Cofanaria, de Francesco Ambra, na ocasião do casamento de Francesco de Medici com Joana da Áustria. Apesar do tema mitológico, baseado no Asno de Ouro de Lúcio Apoleio (COELHO, 2000, p. 32), o caráter cênico da apresentação foi inspirado "em um desfile de carnaval daquele mesmo ano e que apresentou um quadro genealógico dos deuses e deusas da Antiguidade" (ALBERTI DA ROSA, 2010, p. 12), que por sua vez se baseou na Genealogia degli Dei de’Gentili, de Giovanni Boccacio, obra-chave para a fundamentação do neoplatonismo. Para além da mera ilustração cênica, porém, este gênero gradualmente desenvolve uma estrutura narrativa própria, tornando-se assim independente das peças teatrais com as quais dividia os espetáculos. Personagens alegóricos e mitológicos são incluídos, e em sua representação são empregados cantores e formações instrumentais cada vez mais elaboradas. Nas últimas décadas do século XVI, os intermédios já constituíam peças complexas, contando com "a adição de máquinas, desfiles, luzes, espelhos e o que mais houvesse disponível de aparato de efeitos especiais" (ALBERTI DA ROSA, 2010, p. 11), compondo espetáculos suntuosos que eram utilizados pela corte "para impressionar convidados com a riqueza e liberalidade do anfitrião"9 (TARUSKIN, 2010, p. 803).

Os intermédios apresentados em 1589 foram os que se tornaram os mais emblemáticos, devido à riqueza do material encomendado e da execução cênica e musical. Organizado pelo conde Bardi, o espetáculo de 1589 contava com composições de Emilio de' Cavalieri, Luca Marenzio (1553?-1599), Jacopo Peri Giulio e Caccini, sobre textos que o libretista Ottavio Rinuccini criou a partir da peça La Pellegrina, de Girolamo Bargagli. Embora o estilo monódico não seja o único utilizado nos intermédios de 1589, muitas das peças apresentam características semelhantes às encontradas nas primeiras óperas pouco mais de uma década mais tarde, incluindo linhas de baixo que apontam que o acompanhamento que ficaria conhecido como baixo contínuo já fazia parte da prática musical neste contexto. A elaboração e o sucesso de intermédios como os de 1589 certamente constituem um passo fundamental para o desenvolvimento do stile rappresentativo, estilo este que viria a representar, com o surgimento dos primeiros dramas musicados, uma espécie de consumação máxima dos ideais deste círculo de compositores ligados à nobreza florentina.

\section{Antecedentes do stile rappresentativo}

Para a historiografia musical, os princípios poéticos e as práticas composicionais erigidas pela geração de Peri são o fenômeno que caracteriza a ruptura de estilo que marca o fim da renascença e o início do barroco. Aos contemporâneos deste movimento, porém, elas caracterizavam um prolongamento natural ou mesmo uma radicalização de uma das características mais essenciais do renascimento: a busca pela retomada dos ideais artísticos e literários da antiguidade.

É certo que, analisando historicamente, esta tentativa de uma retomada mais verdadeira ou radical daquilo que teriam sido os fundamentos da prática musical na antiguidade de fato acabaria significando uma ruptura com as práticas renascentistas a ponto de marcar o início de um novo estilo, que muito mais tarde ficaria conhecido como barroco. A ruptura rumo ao barroco, porém, não se deve à oposição ao ideal renascentista de arte em termos gerais, mas sobretudo à oposição específica a uma prática que os monodistas acreditavam justamente distanciar-se deste ideal: a polifonia. Em outras palavras, a tentativa era empre- 
ender uma reforma da música em direção às suas raízes clássicas, opondo-se aos excessos formais da escrita polifônica e adequando-a a novas leituras do que teria sido a música da antiguidade (e sobretudo sua relação com o drama). Trata-se antes de uma reestruturação dos ideais renascentistas de arte, e esta reestruturação pode ser entendida como uma atualização destes ideais à luz de novos documentos sobre a música e o teatro da antiguidade, seguida de um movimento de forte especulação artística em torno deste ideal renovado.

Um dos fatores que contribuíram de maneira significativa a este estudo renovado sobre os ideais artísticos e morais da antiguidade foi a fuga dos eruditos gregos que viviam no Império Bizantino para a Itália quando, em 1453, a capital do Império Bizantino foi tomada pelos Turcos Otomanos. Em contato com o vasto material trazido pelos bizantinos, os humanistas italianos puderam se dedicar ao estudo de fontes até então desconhecidas na Europa, o que resultou em mudanças em relação à visão que se tinha anteriormente sobre a filosofia e as artes entre os gregos e romanos. A leitura deste material inédito logo teve impacto sobre o estudo e a prática musical, como descreve a História da Música de Grout e Palisca:

\begin{abstract}
A leitura do tratado de Boécio ${ }^{10}$ enquanto texto clássico, e já não como base para a aprendizagem profissional, na escola de Vittorino de Feltre para jovens e nobres talentosos, fundada em 1424 na corte de Mântua, pode ser considerada como um marco que assinala o início dos novos estudos sobre os primórdios gregos da teoria musical. Não muito depois, os mais importantes tratados musicais gregos foram redescobertos em manuscritos trazidos para o ocidente por gregos emigrados ou por caçadores italianos de manuscritos como um fruto do seu saque em Bizâncio. Entre eles contavam-se os tratados de Bacchius Senior, Aristides Quintiliano, Cláudio Ptolomeu, Cleónides, Euclides e um outro então atribuído a Plutarco. Também conhecidos da época eram o capítulo sobre a música dos Problemas do pseudo-Aristóteles, os Deipnosofistas de Ateneu, obra que contém uma longa passagem sobre a música, os oito livros da Política de Aristóteles e passagens relativas à música dos diálogos de Platão, em particular da República e das Leis. Todos estes textos estavam traduzidos para latim já em finais do século XV, se bem que algumas das traduções fossem feitas apenas para uso particular dos estudiosos e não tivessem grande circulação. (GROUT e PALISCA, 2001, p. 185)
\end{abstract}

Os estudos e as formulações teóricas decorrentes do contato com este novo material se somaram ao cânone musical legado pelos estudos de teóricos medievais e renascentistas que trataram da música da antiguidade. O novo material, no entanto, permitiria um questionamento ainda mais fundamentado da prática da polifonia, na medida em que a nova visão da música da antiguidade era utilizada para corroborar uma prática musical que tentava conciliar expressividade e simplicidade numa fusão de música com elementos mitológicos e cênicos.

Em A sombra de Orfeu: o neoplatonismo renascentista e o nascimento da ópera (2010), Ronel Alberti da Rosa elenca fatores que determinaram o surgimento do gênero operístico, que segundo ele teria como primeiro grande êxito o Orfeo de Claudio Monteverdi (1567-1643). Esta evolução, que necessariamente passou pelo cultivo do neoplatonismo na filosofia e nos gêneros literários, pelas práticas musicais do heterogêneo período renascentista e por uma longa discussão sobre os estilos polifônico e homofônico, viria a culminar com aquilo que Alberti da Rosa considera a afirmação de um dos maiores ideais de toda a renascença. Este ideal equivale à criação de uma plataforma de representação que permitiria evocar e mover os afetos humanos, sintetizando num todo único a retomada de uma maneira natural de cantar e a expressividade que a experimentação harmônica e melódica permitia conferir ao texto, aliado ao ideal, resumido nas palavras do poeta neoplatônico 
Pierre Ronsard, de revelar "por meio de lendas agradáveis e coloridas os segredos que elas não seriam capazes de compreender se a verdade lhes fosse abertamente exposta" (apud COELHO, 2000, p. 31).

Alberti da Rosa compreende o momento em que a monodia se manifesta como um prolongamento ou uma fase final da renascença:

À luz da revalorização dessa herança, entendemos que o Barroco não é a decadência do Renascimento, é o segundo grande momento desse período e a tomada de um novo fôlego. Muito mais coerente é considerá-lo como a fase em que a Renascença supera seus conflitos inerentes sem simplesmente superpô-los de modo forçado, e sim tomando deles consciência e transformando-os em energia emocional subjetiva. (2010, p. 31)

Tendo em conta que Alberti da Rosa analisa sobretudo a fase inicial do barroco, sua leitura tem sentido não apenas por compreender o barroco como o período de consumação de ideais renascentistas e a resolução de seus conflitos. Há uma cronologia especial no caso da música que faz desta fase um período muito próximo do que pode ser considerado a alta renascença musical ${ }^{11}$.

Compreendendo o conceito de 'classicismo' da renascença como a "harmonia alcançada”, termo que Ernst Gombrich utiliza em sua História da Arte (2006) para se referir ao período da alta renascença nas artes visuais (a partir de c.1500), este mesmo classicismo não teria sido alcançado na música antes da metade deste mesmo século, quando o equilíbrio estilístico da música polifônica é adquirido e seus parâmetros técnicos estabelecidos. "O notável codificador da ars perfecta"12, afirma Taruskin (2010, p. 586), foi Gioseffo Zarlino (1517-1590), que através do tratado Le Institutione Harmoniche (1558) permitiu uma "organização do estilo aperfeiçoado em regras permanentes"13 (idem).

Tendo em consideração que Zarlino é o primeiro teórico a aceitar e estabelecer a tríade como padrão de acorde consonante (ou harmonia perfetta) (TARUSKIN, 2010, p. 187) ou a associar os modos maior e menor à representação de diferentes afetos, observamos o quanto o estabelecimento teórico da perfeição renascentista está próxima de sua quebra. Assim como nas artes visuais cerca de meio século antes, o alto renascimento na música não duraria mais que uma geração entre a cristalização do estilo e sua substituição pelo maneirismo, caracterizando o que o teórico da arte Heinrich Wölfflin chama de "cume estreito" (apud HAUSER, 2003, p. 368). Quando o tratado de Zarlino é publicado, Peri, Caccini e os demais precursores da monodia já estão vivos, e alguns dos gêneros que dariam origem ao stile rappresentativo já são utilizados na corte florentina.

Dentro desta cronologia, aquilo que Alberti da Rosa (2010, p. 31) denomina a "segunda grande fase da renascença” equivaleria ao maneirismo na música. Esta designação faz sentido se considerarmos que nas artes visuais o maneirismo representa uma espécie de prolongamento estilístico da renascença, em que a maniera (ou o 'estilo') dos artistas se apresenta realçado em relação aos padrões clássicos, estabelecidos pelos artistas da geração imediatamente anterior. Para Arnold Hauser, a brevidade dos princípios clássicos, transpostos no mesmo instante em que são alcançados, se deu

talvez porque o equilíbrio que encontrou expressão artística no classicismo do Cinquecento fosse desde o início mais um ideal e uma ficção do que uma realidade, e porque a Renascença, como sabemos, permaneceu até o último instante uma época essencialmente dinâmica, incapaz de encontrar satisfação completa em qualquer solução proposta para seus problemas. (2003, p. 368-369) 
A equivalente inquietação artística com relação aos modelos clássicos recentemente estabelecidos, no caso da música, se dá justamente na geração de Jacopo Peri e Giulio Caccini, compositores que buscaram elaborar um estilo expressivo e individualizado, ao qual o formalismo regrado da polifonia descrita por Zarlino não oferecia respostas.

Esta elaboração é descrita por Alberti da Rosa como ‘experimentos notáveis’ (2010, p. 10) que tiveram espaço durante toda a segunda metade do século XVI - uma espécie de busca constante por ideais que seriam alcançados apenas com o surgimento do drama musical. "Entre os precursores", afirma o autor, "três gêneros mais se aproximaram do resultado desejado: a favola pastorale, a commedia madrigalesca ${ }^{14}$ e o intermezzo, ricos em contribuições, mas incompletos para assegurar uma solução definitiva” (idem). Incompletos justamente porque nenhum dos gêneros teria sido suficiente para atingir o que a ópera representará em termos de expressividade musical, estrutura e coerência entre elementos narrativos.

Os intermédios, como mencionamos, contavam nas últimas décadas do século XVI com textos especialmente encomendados para eles, o que resultava numa espécie de narrativa paralela à trama da encenação das fábulas pastorais. Esta evolução muito provavelmente foi uma das principais contribuições à ideia de se criar uma versão musical para um roteiro de cena completo, que não se destinasse aos intervalos da cena, mas fosse uma versão cantada da própria fábula. A proposta se adequava tanto ao ideal debatido na Camerata Fiorentina de recriar a encenação da tragédia grega (que, segundo acreditavam, era inteiramente cantada), quanto aos espetáculos promovidos pela corte, nos quais as apresentações musicais eram especialmente requisitadas e apreciadas. Desta junção surgia a primeira favola in musica, apresentada em Florença em 1597, Dafne, de Jacopo Peri, sobre texto de Ottavio Rinuccini, a qual não se preservou até nossos dias, restando apenas fragmentos (COELHO, 2000, p. 19). Sobre uma adaptação de Rinuccini ao Orfeo de Poliziano seria escrita a segunda favola in musica de Jacopo Peri, Euridice, apresentada em Florença em 1600 durante as comemorações do casamento de Maria de’ Medici com Henrique IV da França. Peri acrescenta à sua favola in musica o prefácio que apresentamos aqui traduzido, sendo esta a primeira publicação a incluir uma explicação das características e dos propósitos do estilo monódico.

\section{Jacopo Peri: L'Euridice (Florença, 1600)}

Em seu prefácio à Euridice, Peri busca justificar a adoção da composição em estilo monódico sobretudo através de concepções ligadas à antiguidade clássica e à suposta maneira com que as tragédias eram então encenadas. O fundamento das suposições de Peri sobre as tragédias gregas, no entanto, se dá de forma indireta. Apesar do entusiasmo pelo estudo da arte e da literatura da antiguidade nos meios florentinos, o que se sabia entre eles sobre a música desta época era insuficiente para deduzir como ela teria soado ou como teriam sido de fato encenadas as tragédias (PALISCA, 2006; ALBERTI DA ROSA, 2010). O interesse de um dos frequentadores da Camerata pelo tema acabaria trazendo algumas informações que, ainda que pouco concludentes, serviram de base à concepção dos pioneiros da monodia. Trata-se de Vicenzo Galilei (1533-1591), alaudista, compositor e teórico que empreendeu inovadoras pesquisas sobre teoria musical. Vicenzo Galilei manteve correspondência com o maior especialista da época em música grega, Girolamo Mei (1519-1594), intelectual que vivia em Roma e que tivera acesso privilegiado a textos antigos através de estudiosos vindos de Constantinopla após o fim do Império Bizantino (COELHO, 2000, p. 42). Segundo Claude Palisca, "embora Peri talvez não tenha participado das discussões da Camerata, ele teria sabido através de Galilei que Mei tinha achado evidências de que as tragédias gregas eram apresentadas com música contínua” (2006, p. 111). 
Esta teoria de que as tragédias gregas eram cantadas, e não recitadas, era discutida entre os eruditos florentinos nas últimas décadas do século XVI, embora não houvesse consenso entre os estudiosos. Entre os defensores da monodia, a crença de que tanto os coros quanto as falas individuais das tragédias fossem cantadas fornecia fundamento para sustentar a relação entre o drama musical que se engendrava e o modelo clássico de declamação dramática. Peri, Rinuccini e Caccini estavam entre os que aceitavam o argumento de Girolamo Mei, baseado na interpretação de um texto de Platão, segundo o qual os modos Hipodórico e Hipofrígio seriam os melhores para os atores no palco, enquanto os outros seriam melhores para os coros. Isto seria a evidência concreta, acreditavam, para deduzir que a tragédia grega era toda cantada, e como tal poderia servir de modelo a um drama cantado moderno. Peri então faz sua aposta, propondo uma solução prática para o problema que se baseava nos estudos de Mei e em sua própria compreensão da maneira clássica de se cantar:

Visto que se tratava de poesia Dramática, e que se deveria imitar com o canto o que se fala (e sem dúvida não se fala cantando), estimei que os antigos Gregos e Romanos (os quais segundo a opinião de muitos cantavam em cena as Tragédias inteiras), usavam uma harmonia que, avançando além da fala comum, se aproxima tanto da melodia do canto que assume a forma de algo intermediário. ${ }^{15}$ (PERI, 1600)

Trata-se de fato de uma proposta prática, pois Peri, enquanto cantor, procurava alcançar em suas próprias performances um estilo que acreditava aproximar-se do modelo da antiguidade clássica, o que reflete um dos principais objetivos entre os humanistas.

Enquanto o texto de Peri tem especial ênfase sobre a descrição daquilo que acredita ser a maneira com que o canto teria sido utilizado na representação das tragédias na antiguidade (e a maneira como ele adapta este canto às demandas de seu próprio tempo), no prefácio de Le Nuove musiche, publicado no ano seguinte, Giulio Caccini se ocupa mais detalhadamente de elementos de performance do canto monódico, ligados especificamente a suas próprias canções. Ambos, no entanto, tem em comum uma evidente preocupação em fundamentar a origem da monodia sobre a premissa da retomada de um estilo de canto que se teria perdido pela tradição musical europeia através do desenvolvimento da polifonia. Esta prática, alegavam, desconectava a música do sentido das palavras, já que a sobreposição de vozes impossibilitava a compreensão do texto. Livre do condicionamento à elaborada arquitetura da polifonia, a melodia do canto solista poderia expressar de forma simples o afeto evocado pelo texto, buscando em seus contornos uma equivalência mais próxima do sentido buscado pelo poeta.

\section{Tradução do prefácio a Le Musiche sopra L'Euridice del Sig. Ottavino Rinuccini, de Jacopo Peri (Florença, 1600)}




\section{A Letori}

Prima, chío vi porga (benigni Lettori) queste Musiche mie, ho stimato conuenirmisi farui noto quello, che m'ha indotto a ritrouare questa nuoua maniera di canto, poichè di tutte operazioni humane, la ragione debbe essere principio, e fonte; $E$ chi non puo renderla ageuolmente da a credere, d'hauer'operato a caso. Benchè da Sig. Emilio del Caualiere, prima chè da ogni altro, chío sappia, con marauligliosa inuenzione ci fusse fatta udire la nostra Musica su le scene; Piacque nondimeno a'Signori Jacopo Corsi, ed Ottauio Rinuccini (fin l'Anno 1594) che io adoperandola in altra guisa, mettesse sotto le nota la favola do Dafne, dal Sig. Ottauio composta, per fare una semplice pruoua di quello che potesse il canto dell'età nostra. Onde veduto, che si trattaua di poesia Dramatica, e che però si doueua imitar col canto chi parla (e senza dubbio non si parlò mai cantando) stimai, che gli antichi Greci e Romani (i quali secondo l'openione di molti cantauano su le Scene le Tragedie intere) vsassero un armonia, che auanzando quella del parlare ordinario, scendesse tanto dalla melodia del cantare, che pigliasse forma di cosa mezzana; E questa è la ragione, onde veggiano in quelle Poesie, hauer' hauuto luogo il Jambo, che non s'innalza, come l'Esametro, mas pure è detto anuanzarsi oltr'a confini, di ragionamentoi familiari. E per ciò tralasciata qualunque altra maniera di canto vdita fin quì, mi diedi tutto a ricercare I imitazione, che si debbe a questi Poemi; e considerai, che quella sorte di voce, che dagli Antichi al cantare fuassegnata, la quale essi chiamauano Diastematica (quasi trattenuta, e sospesa) potesse in parte affrettarsi, e prender temperato corso tra i mouimenti del canto sospesi, e lenti, e queli della fauella spediti, e veloci, \& accomodarsi al proposito mio (come l'accomodauano anch'essi, leggendo le Poesie, \& i versi Eroici) auuincinandosi all'altra del ragionare, la quale continuata appellauano; II che $i$ nostri moderni (benchè forse ad altro fine) hanno ancor fatto nelle musiche loro. Conobbi parimente nel nostro parlare alcune voci, intonarsi in guisa, che vi si puo fondare armonia, e nel corso della fauella passarsi per altre molte, che non s'intuonano, finchè si ritorni ad altra capace di mouimento di nuoua consonanza; \& hauuto riguardo a que'modi, \& a quegli accenti, che nel dolerci, nel rallegrarci, \& in somiglianti cose ci seruono, feci mouere il Basso al tempo di quegli, hor più, hor meno, secondo gli affetti, e lo tenni fermo tra le false, e tra le buone proporzioni, finchè scorrendo per varie note la voce di chi ragiona, arriuasse a quello, che nel parlare ordinario intonandosi, apre la via a nuovo concento; $E$ questo non solo, perchè il corso del ragionare non ferisse l'orecchio (quasi intoppando negli incontri delle ripercosse corde, dalle consonanze più spesse,) ò non paresse in vn certo modo ballare al moto del Basso, e principalmente nelle cose, ò meste, ò graui, richidendo per natura l'altre più liete, più spessi mouimenti: Ma ancora perchè l'Vso delle false, ò scemasse, ò ricoprisse quel vantaggio, che ci s'aggiugne dalla necessità dell'intonare ogni nota, di che per cio fare poteuan forse hauer manco bisogno l'antiche Musiche. E però, (si come io non ardirei affermare questo essere il canto nelle Greche, e nelle Romane favole vsato), così ho creduto esser quello, che solo possa donarcisi dalla nostra Musica, per accomodarsi alla nostra fauella. Onde fatta vdire a quei Signori la mia openione, dimostrai loro questo nuouo modo di cantare, epiacque sommamente, non pure al Signor lacopo, il quale haueua di già composte arie belissime per quella fauola, ma al Signor Piero-Strozzi, al Signor Francesco Cini, \& ad altri molti intendentissimi gentiluomini (che nella nobilità fiorisce hoggi la Musica) come anco a quella famosa, che si può chiamare Euterpe dell'età nostra, la Signora Vettoria Archilei, la quale ha sempre fatte degne del cantar suo Musiche mie, adornandole, non pure do quei gruppi, e di quei lunghi giri di voce, semplici,

\section{Aos leitores}

Antes de oferecer-lhes, caros leitores, esta minha música, considerei conveniente fazer-lhes conhecer aquilo que me induziu a encontrar esta nova forma de canto, pois em todas as ações humanas a razão deve ser princípio e fonte, e aquele que não conseguir fazê-lo facilmente dá a crer que agiu por acaso. Apesar de o Senhor Emilio de Cavalieri, antes de qualquer outro, que eu saiba, com maravilhosa invenção fez ouvir a nossa Música em cena; no entanto satisfez ao Senhor Jacopo Corsi e a Ottavio Rinuccini (desde o ano de 1594) que eu, empregando-a de outra maneira, colocasse em música a fábula de Dafne, escrita pelo Senhor Ottavio, para fazer uma simples experiência do potencial do canto de nossa época. Visto que se tratava de poesia dramática, e que se deveria imitar com o canto o que se fala (e sem dúvida não se fala cantando), estimei que os antigos Gregos e Romanos (os quais segundo a opinião de muitos cantavam em cena as tragédias inteiras), usavam uma harmonia que, avançando além da fala comum, se aproxima tanto da melodia do canto que assume a forma de algo intermediário. E esta é a razão pela qual vemos que naquela poesia há espaço para o Jâmbico, que não se exalta como o hexâmero, mas é dito que avança além dos limites da fala comum. E portanto, rejeitando qualquer outra forma de canto ouvida até agora, me dediquei totalmente a procurar a imitação devida a estes poemas; e considerei que aquele tipo de voz que é atribuído ao canto antigo, que eles chamavam diastemática (meio sustentada e suspensa), poderia algumas vezes acelerar e tomar caminho intermediário entre os movimentos suspensos e lentos do canto e aqueles ágeis e rápidos da fala, e acomodar-se assim ao meu propósito (como se acomodava também à leitura de poesia e versos heróicos), aproximando-se daquela outra maneira de falar, a qual eles chamavam de contínua - o que os nossos modernos (apesar de talvez com outra finalidade) fizeram também na música deles. Reconheci também que no nosso falar algumas palavras são entoadas de uma maneira que pode criar harmonia, e ao longo do discurso passamos por muitas outras que não são entoadas, até retornar a uma outra capaz de movimentar-se a uma nova consonância; e considerando aqueles modos e aqueles acentos que são necessários no lamento, no regojizar-se e casos semelhantes, fiz mover o baixo no tempo deles, às vezes mais, às vezes menos, de acordo com os afetos, e o mantive constante através das falsas e boas proporções [i.e. dissonâncias e consonâncias] até que a voz daquele que declama, passando por várias notas, chegasse àquela que na entonação da fala quotidiana abre caminho a uma nova harmonia. $E$ isto não apenas para que 0 discurso não ferisse o ouvido (como se tropeçando nos encontros das notas repetidas das consonâncias mais frequentes), ou que não parecesse de certo modo dançar de acordo com o movimento do baixo (e principalmente em coisas tristes e graves, requerendo as outras mais felizes naturalmente mais movimento): mas ainda porque o uso das falsas [i.e. dissonâncias] diminuísse ou encobrisse a vantagem adquirida da necessidade de se entonar cada nota, o que talvez não tenha sido necessário na música antiga. No entanto, (apesar de eu não ousar dizer que este era o canto usado nas fábulas gregas e romanas), acredito que é esse o modo que nossa música permite acomodar-se aos nossos discursos. Portanto, tendo feito ouvir minha opinião por estes Senhores, demonstrei-Ihes este novo modo de cantar, que agradou imensamente não apenas o Senhor lacopo [Corsi], o qual já havia composto árias belíssimas para esta fábula, mas também ao Senhor PieroStrozzi, ao Senhor Francesco Cini e muitos outros entendidíssimos cavalheiros (pois a música floresce hoje na nobreza) e também àquela famosa que se pode chamar Euterpe de nossa época, a Senhora Vettoria Archelei, a qual sempre faz minha música digna de seu canto, adornando-a não apenas com aqueles trilos ${ }^{16}$ 
e doppi, che dalla viuezza dell'ingegno suo son ritrouati ad ogn'hora, più per vbbidire all'vso dei nostri tempi, che, perch ella stimi consostere in esse la bellezza, e la forza del nostro cantare, ma anco di quelle, e caghezze, e leggiadrie, che non si possono scriuere, e scriuendole non s'imparano da gli scritti. L'vdì, e la commendò Messer Giouanbattista Jacomelli, che in tutte le parti della musica eccellentissimo, ha quasi cambiato il suo cognome col Violino, in cui egli è mirabile: E per tre Anni continui, che nel Carnauale si rappresentò, fu vdita con sommo diletto, e con applauso vniversale riceuuta, da chiunque vi si ritrouò. ma hebbe miglior ventura la presente Euridice, non perchè la sentirono quei Signori, \& altri valorosi huomini, ch'io nominai, e di più il Signor Conte Alfonso Fontanella, \& il Signor Orazio Vecchi, testimoni nobilissi del mio pensiero, ma perchè fu rappresentata ad vna Reginasi grande, \& tanti famosi Principi d'Italia, e di Francia, e fu cantata da più eccellenti Musici de nostri tempi; Tra i quali Signor Francesco Rasi, nobile Aretino rappresentò Aminta, il Signor Antonio Brandi Arcetro, \& e il Signor Mechior Palantrotti, Plutone; e dentro alla Scena fu sonata da Signori per nobilità di sangue, e per eccellenza di musica IIIustri, II Signor Jacopo Corsi, che tanto spesso ho nominato, sonò vn Grauicembalo; \& il signor Don Grazia Montaluo, vn Chitarrone, Messer Giouanbattista dal Violin, Vna Lira grande; e Messer Giouanni Lapi, vn Liutto grosso: E benchè fin allhora l'hauessi fatta nel modo appunto, che hora viene in luce: Non dimeno Giulio Caccini (detto Romano) il cui sommo valore è noto al Mondo, fece l'arie d'Euridice, \& alcune del Pastore, e Ninfa del Coro, e de'Cori Al canto, al ballo, Sospirate, e Poi che gli Eterni Imperi. E questo, perchè doueuano esser cantate da persone dependenti da lui, le quali Arie si leggono nella sua composta, e stampata pur dopo, che questa mia fu rappresentata a sua Maestà Cristianissima.

Riceuetela però benignamente cortesi Lettori, e benchè io non sia arriuato con questo modo, fin doue mi pareua di poter giugnere (essendo stato freno al mio corso il rispetto della nouità), graditela in ogni modo; e forse auuerà, ch'in altra occasione io vi dimostri cosa più perfetta di questa: Intanto mi parrà d'hauer fatto assai, hauendo aperta la strada al valor'altrui, di camminare per le mie orme alla gloria, doue a me non è dato di poter peruenire. E spero, che l'vso delle false, sonate, e cantate senza paura, discretamente, \& appunto (essendo piaciute a tanti, e si valorosi huomini) non vi saranno di noia, massine nell'arie più meste, e più graui, d'Orfeo, d'Arcretro, e di Dafne, rappresentata con molta grazia da Jacopo Giusti, fanciulletto Luchese. E viuete lieti. e com aqueles longos giros de voz, simples e duplos, mas com a vivacidade de engenho que encontra a cada momento, mais para adequar-se ao uso do nosso tempo do que por acreditar que nisto se encontra a beleza e a força do nosso cantar, mas também com aqueles gracejos e encantos que não é possível escrever, e se escrito não se aprende a partir da escrita. A ouviu e elogiou o Mestre Giovanbattista Jacomelli, excelentíssimo em toda parte da música, que quase mudou seu sobrenome para Violino, instrumento no qual é admirável. E por três anos consecutivos, quando apresentada no carnaval, foi ouvida com muito deleite e recebida com aplauso universal por qualquer um que a ouviu. Mas a presente Euridice teve melhor sorte, não porque foi ouvida por aqueles Senhores e outros homens valorosos que nomeei, e também o Senhor Conde Alfonso Fontanella e o Senhor Orazio Vecchi, testemunha nobilíssima de meu pensamento, mas porque foi apresentada diante de uma grande Rainha e tantos famosos príncipes da Itália e da França e foi cantada pelos mais excelentes músicos de nosso tempo. Entre os quais o Senhor Francesco Rasi, nobre Aretino, que representou Aminta; Senhor Antonio Brandi, Arcreto, e o Senhor Mechior Palantrotti, Plutone. E por trás da cena o Senhor Jacopo Corsi, llustre por nobreza de sangue e por excelência de música, que mencionei muitas vezes, tocou o cravo, e o Senhor Don Grazia Montalvo o Chitarrone, Messer Giovanbattista do violino uma lira grande e Messer Giovanni Lapi um grande alaúde. E embora até então eu tivesse feito do modo como agora vem à luz, no entanto Giulio Caccini (dito Romano), cujo grande valor é conhecido pelo mundo, fez as árias da Euridice e algumas daquelas dos Pastores, e a Ninfa do coro, e os Coros Al canto, al ballo, Sospirate e Poi che gli Eterni Imperi. E isto porque deveriam ser cantados por pessoas sob sua direção, e estas árias se encontram na sua composição, e impressa depois que esta minha foi representada diante de sua Majestade Cristianíssima.

Receba então amavelmente, cortês leitor, e embora eu não tenha chegado desta maneira à finalidade que parecia poder atingir (a consideração da novidade sendo o freio do meu percurso), acolha-a mesmo assim, e talvez em outra ocasião eu mostre coisa mais perfeita que esta: no entanto me parece que fiz bastante, tendo aberto caminho para outros que com seus méritos caminharão seguindo meus passos rumo à glória que não me foi permitido alcançar. E espero que o uso das falsas [i.e. dissonâncias], tocadas e cantadas sem medo, com discrição e cuidado (sendo agradável a tantos e tão valorosos homens), não lhes cause aborrecimento, sobretudo nas árias mais tristes e graves de Orfeo, de Arcreto e de Dafne, representada com muita graça por Jacopo Giusti, jovem rapaz de Lucca. E viva feliz.

\section{Aspectos de performance no prefácio de Jacopo Peri}

A busca pela expressão dos afetos do texto através da música - uma das demandas fundamentais relacionadas ao surgimento do stile moderno - traz ao campo musical o ideal humanista de individualismo. A expressão das paixões daquele que canta versos ou do personagem do drama musical se traduz na preferência por uma voz solista como portadora do pathos poético. Desta forma, uma nova hierarquia se estabelece entre os enunciadores da expressão, rivalizando com a equivalência de importância entre as vozes que caracteriza a polifonia renascentista.

Como primeira publicação em forma de explicação do estilo monódico, o prefácio de Peri traz uma abordagem sobre o canto e o acompanhamento que mostra uma percepção de diferentes papéis desempenhados por ambos na expressão musical. Dentro da nova hierarquia expressiva estabelecida pela monodia, a linha melódica do canto se destaca 
não apenas por seu contorno elaborado, mas por sua precedência com relação ao discurso emocional. A interpretação do canto parece ser tão importante quanto esta diferenciação já evidente pela própria partitura. Peri mostra uma preocupação especial em descrever a maneira de se cantar esta música, tentando apontar características de performance que a partitura (de escrita bastante simples) não poderia dizer por si só. A descrição de Peri aponta para uma liberdade especial quanto à duração das palavras e das sílabas, a fim de que estas possam estar a meio caminho entre a declamação e o canto (ou seja, um estilo de canto que procure imitar aproximadamente, mas não fielmente, o ritmo da palavra declamada, trazendo para o canto as ênfases dramáticas da recitação e tornando o próprio canto algo mais natural).

A preocupação com a liberdade expressiva do canto - e consequentemente com o estabelecimento das características emocionais dos personagens ao longo da trama - se relaciona à maneira que ele crê que os antigos teriam trabalhado a relação do canto com a fala, mas também segundo sua própria concepção de imitação da fala através do canto. Por tratar-se justamente disso a novidade na proposta de Peri (a imitação da fala com o canto e a consequente possibilidade de trazer para a música a expressividade da declamação), é esta característica de sua música que ele mais procura expor e justificar.

O acompanhamento instrumental não recebe uma explicação técnica no que diz respeito à estrutura harmônica do acompanhamento (uso de cifras, formação dos acordes, conduções de vozes etc), mas apenas à função de fornecer uma base ao cantor, com ênfase na questão rítmica da declamação do texto - o que se mostra sua preocupação principal também no que se refere ao acompanhamento. Seguindo o ritmo da voz, o instrumentista pode oferecer apenas alguns apoios em trechos em que a parte do canto necessite de maior liberdade (como nos lamentos), ou assumir caráter rítmico mais acentuado em trechos alegres.

Quando descreve o acompanhamento, as notas que interessam a Peri são aquelas que através do canto podem imitar as inflexões da declamação. Peri acredita que a fala traz um certo contorno melódico que se evidencia mais em algumas sílabas, enquanto que nas demais se utiliza da voz de forma menos melódica. Estes pequenos ápices melódicos da fala são para Peri as notas que se deve acompanhar, fazendo coincidir a eles os apoios harmônicos fornecidos pelos instrumentos:

Reconheci também que no nosso falar algumas palavras são entoadas de uma maneira que pode criar harmonia, e ao longo do discurso passamos por muitas outras que não são entoadas, até retornar a uma outra capaz de movimentar-se a uma nova consonância; e considerando aqueles modos e aqueles acentos que são necessários no lamento, no regozijar-se e casos semelhantes, fiz mover o baixo no tempo deles, às vezes mais, às vezes menos, de acordo com os afetos, e o mantive constante através das falsas e boas proporções [i.e. dissonâncias e consonâncias] até que a voz daquele que declama, passando por várias notas, chegasse àquela que na entonação da fala quotidiana abre caminho a uma nova harmonia. ${ }^{17}$ (PERI, 1600)

A chave para que o canto possa encontrar alguma equivalência com as inflexões da fala seria portanto encontrar os apoios que as palavras recebem na declamação, os quais recebiam ênfase na própria escrita musical, e enfatizar musicalmente estes apoios. A solução musical adotada para essa imitação da declamação incluía o entendimento de que apenas as sílabas mais fortes da poesia deveriam receber uma harmonia como base (tocada pelo acompanhador), de forma que entre um apoio e outro o cantor se visse livre para dispor entre elas as palavras num ritmo que estivesse entre o canto e a fala. Nesta concepção do papel do acompanhamento está a principal dica sobre como este acompanhamento era feito. 
Como aponta Palisca, no Dialogo della musica antica, e della moderna (1581), “Galilei cita uma queixa de Platão de que certos cantores se acompanhavam numa maneira chamada proschorda ao invés de symphonon, ou seja, com uma variedade de acordes e embelezamentos ao invés de simples harmonias” (PALISCA, 2006, p. 117). Se Peri buscou também no acompanhamento de sua monodia os modelos gregos, o acompanhamento esperado por ele provavelmente utiliza sobretudo apoios harmônicos em estilo cordal junto aos acentos do texto sem muitas passagens entre estes apoios, adequando-se portanto à interpretação de Galilei do acompanhamento que Platão chama de symphonon (idem).

Desta forma, o acompanhamento proposto por Peri, sendo mais cordal (ou symphonon) do que floreado (ou proschorda), surge como uma solução que manteria a uma só vez a liberdade rítmica do cantor e o suporte harmônico que entendia como necessário ao canto. Entre os apoios do canto (com os quais devem coincidir os apoios do acompanhamento), o cantor poderá imitar col canto chi parla, ou seja, encontrar na imitação da expressividade da entonação falada os afetos da declamação que se adequem ao texto cantado.

Do ponto de vista prático, este acompanhamento seria o mais condizente com a ênfase na liberdade rítmica do canto, já que esta liberdade se torna tão menos viável quanto mais o instrumentista incluir melodias e ornamentos entre os apoios. Este é um problema facilmente observável quando se procura florear o acompanhamento neste tipo de repertório, pois dificilmente as notas acrescentadas encontrarão equivalência com o ritmo livre da imitação da fala, tornando a interação entre canto e instrumento confusa ou desencontrada, o que tende a anular a própria ideia de clareza da enunciação.

O entendimento de que o acompanhamento proposto por Peri procura recriar o estilo proschorda é também condizente com o fato de que do estilo característico de canto meio-recitado das primeiras óperas deriva aquilo que mais tarde ficou conhecido como recitativo (TARUSKIN, 2010) - embora talvez se possa crer que o recitativo tenha se tornado, ao longo das décadas posteriores, mais arquetípico no que diz respeito à ideia de contrapor apoio e declamação livre. O uso do recitativo, que gradualmente vai sendo destinado a momentos de menor intensidade dramática como narrativas e diálogos (em oposição aos trechos de maior expressividade como árias, duetos etc), fez da possibilidade do descanso temporário do canto melódico durante a trama um elemento de ligação entre Jacopo Peri e a tradição operística italiana até o fim do século XIX (assim como em outros países, que adquirem suas próprias maneiras de trabalhar os trechos recitados).

\section{Considerações finais}

O prefácio de Peri, como vimos, cumpre função não apenas de expor o estilo adotado por ele, mas de justificar este estilo num ambiente de amplo debate sobre diferentes tendências composicionais. Certamente consciente de que se tratava da primeira publicação a trazer uma explicação deste estilo, Peri procurou justificar com argumentos de autoridade sua prática como uma espécie de retomada das características da tragédia, mas também mostrou uma preocupação evidente em descrever a performance esperada para a música que publicava. Fora dos círculos florentinos, ainda que o novo estilo pudesse alcançar sucesso (como de fato sucedeu), aqueles que quisessem executar estas obras talvez não conhecessem as sutilezas da nova proposta, tendendo a manter características do canto ao qual estavam acostumados ou incluir elementos de expressão não condizentes com a proposta estilística idealizada por Peri e os compositores de seu círculo. 
Uma terceira preocupação seria a de evidenciar uma concepção e um uso pessoal da monodia. Embora tenha contado com a participação de Jacopo Corsi e Giulio Caccini, respectivamente na composição de Dafne e Euridice, Peri é conhecido como o compositor pioneiro da ópera. Este gênero seria, no princípio, fruto de suas próprias especulações e soluções para o drama musicado, e nele se encontra sua maneira particular de utilizar a monodia que então tomava forma.

Embora a fundamentação apresentada por Peri se ancore na interpretação de textos clássicos, fica evidente durante o prefácio que as principais soluções práticas encontradas pelo autor passam por sua própria experimentação do canto. Ao procurar fazer reviver em sua música os ideais clássicos, Peri não se mostra concludente no que diz respeito à fidelidade com a música da antiguidade. No melhor estilo 'humilde servo das musas', o autor admite que seu canto talvez tenha algo de adaptação moderna aos ideais antigos, apontando a uma finalidade de comprazer os gostos de seu próprio tempo. Como prudente ressalva, Peri acrescenta a seus argumentos sobre seu próprio estilo e o modelo de canto da antiguidade: "No entanto, (apesar de eu não ousar dizer que este era o canto usado nas fábulas gregas e romanas), acredito que é esse o modo que nossa música permite acomodar-se aos nossos discursos" (PERI, 1600).

Apesar de ser conhecido como um texto no qual as relações entre a monodia e a imitação do canto da antiguidade estão bastante relacionadas, a tentativa de descrever a parte prática do canto é tão interessante quanto a possibilidade que Peri nos permite de acompanhar o raciocínio que o levou à formulação de seu drama musical. As respostas de Peri à busca pela liberdade e expressividade do canto e à adequação do acompanhamento a este discurso são um misto engenhoso de evidências históricas dos ideais de aproximação da antiguidade clássica com experimentações práticas segundo uma poética própria de um período complexo e artisticamente especulativo. Em outras palavras, o prefácio de Peri apresenta uma aposta artística como solução pessoal para conflitos imanentes à época e ao ambiente de Peri, em forma de canalização de objetivos e soluções num resultado altamente inventivo e emocional.

\section{Notas}

1 Segundo The New Grove Dictionary of Music and Musicians, o stile rappresentativo é um dos estilos afetivos que emergem com a "nova música" no início do século XVII, podendo referir-se aos madrigais da seconda pratica, às canções solo e duetos de compositores como Giulio Caccini e até concertos sacros. O termo, portanto, "pode denotar musica para o teatro, música em estilo recitativo ou música que adota uma abordagem particularmente dramática e emocional na representação de seu texto" [can denote music for the theatre, music in a recitative style, or music that adopts a particularly dramatic or emotional approach to representing its text].

2 Ronel Alberti da Rosa (2010) aponta que quando o novo gênero surge há uma procura por nomes para designá-lo, como favola in musica, dramma in musica, ou opera in musica (p. 9). Segundo Lauro Machado Coelho a designação de “ópera” "se tornará comum na Inglaterra por volta de 1650; na França e países germânicos só se impõe no século XVII e, na própria Itália, é de utilização bem mais tardia” (2000, p. 50).

3 Um dos textos que ilustram bem esta crítica é o Dialogo della musica antica et della moderna, de Vicenzo Galilei, publicado em 1581 em Florença, que pode ser encontrado parcialmente traduzido em O canto dos afetos: um dizer humanista, de Ibaney Chasin (2004). A tradução de outro trecho para o inglês pode ser lido em Source Readings in Music History, editado por Oliver Strunk (a versão consultada é a revisada por Leo Treitler, 1998).

4 the begining of the codification of basso continuo, coinciding precisely with the development of the stile rappresentativo and the breaking away from contrapuntal polyphony in accompaniment.

5 Segundo volume de cinco da Oxford History of Western Music, publicada originalmente em 2005 (aqui foi utilizada a segunda edição, de 2010).

${ }^{6}$ what actually happened around 1600mwas no sudden musical revolution, but only the emergence into print of musical practices that had been in the process of formation over the whole preceding century. 
7 to the authoritative medium of print.

8 (ver MULLER, 2006, p. 213).

9 meant to impress invited guests with their noble host's wealth and liberality.

${ }^{10}$ De institutione musica (c. 500), de Anício Mânlio Torquato Severino Boécio.

${ }^{11}$ O termo "alta renascença", comum no estudo da história da arte, diz respeito ao período correspondente às primeiras décadas a partir de cerca de 1500, representado por artistas como Leonardo da Vinci (1452-1519) e Michelangelo Buonarotti (1475-1564). Corresponde, portanto, ao período de cristalização formal e estética da renascença, quando esta adquire alto grau de desenvolvimento e autoridade estilística. No caso da música, a relação aqui apresentada se dá com a geração de Giovanni Pierluigi da Palestrina (1525-1594) e Orlando di Lasso (1532-1594), compositores que representam um elevado grau de consolidação do estilo polifônico renascentista.

12 The oustanding codifier os the ars perfecta.

${ }^{13}$ casting of the perfected style in permanent rules.

14 Segundo Lauro Machado Coelho (2006), a commedia madrigalesca, que possui estreito vínculo com a commedia dell' arte, desenvolve-se como "resultado da utilização dramática do madrigal - o tipo de composição vocal profana a várias vozes, que evoluiu a partir das formas de canção polifônica - a frottola italiana, a part-song inglesa -, atingindo o máximo esplendor no século XVI nas mãos de compositores como Luca Marenzio, Carlo Gesualdo da Venosa, Claudio Monteverdi ou Sigismondo d’India” (p. 34).

${ }^{15}$ Onde veduto, che si trattaua di poesia Dramatica, e che però si doueua imitar col canto chi parla (e senza dubbio non si parlò mai cantando) stimai, che gli antichi Greci e Romani (i quali secondo l'openione di molti cantauano su le Scene le Tragedie intere) vsassero un armonia, che auanzando quella del parlare ordinario, scendesse tanto dalla melodia del cantare, che pigliasse forma di cosa mezzana.

${ }^{16}$ gruppi no original, trills segundo a tradução da edição de Oliver Strunk e Leo Treitler (1998). O trilo conforme conhecemos hoje é o que se assemelha mais ao que se chamava gruppo. O que se chamava de trillo na época equivale à repetição contínua da mesma nota, como se pode obsevar na demonstração de Caccini de trillo e gruppo em As novas músicas (2006, p. 221).

${ }_{17}$ Conobbi parimente nel nostro parlare alcune voci, intonarsi in guisa, che vi si puo fondare armonia, e nel corso della fauella passarsi per altre molte, che non s'intuonano, finchè si ritorni ad altra capace di mouimento di nuoua consonanza; \& hauuto riguardo a que'modi, \& a quegli accenti, che nel dolerci, nel rallegrarci, \& in somiglianti cose ci seruono, feci mouere il Basso al tempo di quegli, hor più, hor meno, secondo gli affetti, e lo tenni fermo tra le false, e tra le buone proporzioni, finchè scorrendo per varie note la voce di chi ragiona, arriuasse a quello, che nel parlare ordinario intonandosi, apre la via a nuovo concento.

\section{Referências}

ALBERTI DA ROSA, Ronel. A Sombra de Orfeu: o neoplatonismo renascentista e o nascimento da ópera. Porto Alegre: EDIPUCRS, 2010.

CACCINI, Giulio. As Novas Músicas. In: MULLER, Heloisa. Le Nuove Musiche: história e estilo no canto de Giulio Caccini. Tese de Doutorado. Escola de Comunicação e Artes da Universidade de São Paulo, 2006. São Paulo: USP, 2006, 228 p.

CHASIN, Ibaney. O Canto dos Afetos: um dizer humanista. São Paulo: Perspectiva, 2004.

COELHO, Lauro Machado. A Ópera Barroca Italiana. São Paulo: Perspectiva, 2000.

FEDERICI, Conrado Augusto Gandara. Giulio Caccini e suas novas músicas: um elogio ao canto. Tese de Doutorado - Faculdade de Educação da Universidade Estadual de Campinas, 2009. Campinas: UNICAMP, 2009. 182 p.

GOMBRICH, Ernst Hans. A História da Arte. Tradução: Cristiana de Assis Serra. Rio de Janeiro: LTC, 2013.

GROUT, Donald J.; PALISCA, Claude V. História da música ocidental. Tradução: Ana Luísa Faria. Lisboa: Gradiva, 2001.

HAUSER, Arnold. História social da arte e da literatura. Tradução: Álvaro Cabral. São Paulo: Martins Fontes, 2003. 
MULLER, Heloisa. Le Nuove Musiche: história e estilo no canto de Giulio Caccini. Tese de Doutorado. Escola de Comunicação e Artes da Universidade de São Paulo, 2006. São Paulo: USP, 2006, 228 p.

NUTI, Giulia. The Performance of Italian Basso Continuo: style in keyboard accompaniment in the seventeenth and eighteenth centuries. Farnham: Ashgate, 2007.

PALISCA, Claude V. Music and Ideas in the Sixteenth and Seventeenth Centuries. Champaign: University of Illinois, 2006.

PERI, Jacopo. Le Musiche sopra L'Euridice del Sig. Ottavino Rinuccini. Florença: Giorgio Marescotti, 1600 .

STRUNK, Oliver; TREITLER, Leo (Eds.). Source Readings in Music History. New York: W. W. Norton: 1998.

TARUSKIN, Richard. Oxford History of Western Music. I: Music in the Seventeenth and Eighteenth Century. New York: Oxford University Press, 2010.

VIADANA, Lodovico. Li Cento Concerti Ecclesiastici, a Una, a Due, a Tre \& a Quattro voci. Con il Basso continuo per sonar nell'organo. Disponível em: <http://www.bassus-generalis.org/>. Acesso em: 03/06/2010.

ZARLINO, Gioseffo. Le Istitutioni harmoniche. Veneza, 1558. Disponível em: <http://ks.imslp. info/files/imglnks/usimg/6/6c/IMSLP317594-PMLP156553-leistitutionihar00zarl.pdf>. Acesso em: 10/08/2014.

Gustavo Angelo Dias - Professor adjunto do Centro de Artes da Universidade Federal de Pelotas (UFPel), onde ministra disciplinas nas áreas de estética e metodologia de pesquisa em artes. Formado em cravo pela Universidade Estadual de Campinas (UNICAMP), possui mestrado em musicologia pela Universidade Federal do Paraná (UFPR) e doutorado em fundamentos teóricos pela UNICAMP. Em 2014 publicou o livro Tratados portugueses de baixo contínuo: a influência de Francesco Gasparini pela Novas Edições Acadêmicas (Portugal).

Helena Jank - Professora titular do Instituto de Artes da Universidade Estadual de Campinas (UNICAMP), onde pertenceu ao grupo de professores que participaram da criação do Instituo de Artes e mais tarde do curso de Música da UNICAMP. Foi coordenadora do programa de Pós-Graduação em Música entre 1995 e 1999 e Diretora do Instituto de Artes entre 1999 e 2003. Foi responsável pelos cursos de cravo, música de câmara e baixo cifrado, e como colaboradora docente na disciplina História da Música, para os períodos barroco e clássico. Sua produção artística concentra-se principalmente em repertório do período barroco. Tem se dedicado também à divulgação da música brasileira para cravo, resgatando o repertório do passado e estimulado a criação de novas obras para este instrumento. 